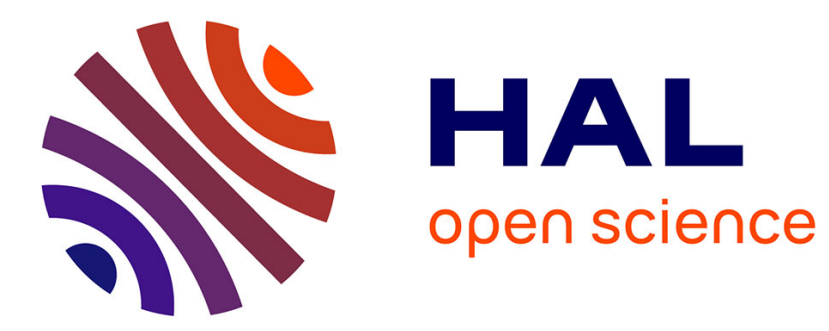

\title{
Predicting changes in the color of powders: Does Melamed's model fit to real industrial powders?
}

Hélène Garay, Olivier Eterradossi, Ali Benhassaine

\section{To cite this version:}

Hélène Garay, Olivier Eterradossi, Ali Benhassaine. Predicting changes in the color of powders: Does Melamed's model fit to real industrial powders?. Color Research and Application, 2004, 29 (6), pp.413-419. 10.1002/col.20058 . hal-03252967

\section{HAL Id: hal-03252967 https://hal.mines-ales.fr/hal-03252967}

Submitted on 8 Jun 2021

HAL is a multi-disciplinary open access archive for the deposit and dissemination of scientific research documents, whether they are published or not. The documents may come from teaching and research institutions in France or abroad, or from public or private research centers.
L'archive ouverte pluridisciplinaire HAL, est destinée au dépôt et à la diffusion de documents scientifiques de niveau recherche, publiés ou non, émanant des établissements d'enseignement et de recherche français ou étrangers, des laboratoires publics ou privés. 


\section{Predicting Changes in the Color of Powders: Does Melamed's Model Fit to Real Industrial Powders?}

\section{Hél ène Garay, ${ }^{1, *}$ Olivier Eterradossi, ${ }^{1}$ Ali Benhassaine ${ }^{2}$}

${ }^{1}$ Ecole des Mines d'Alès, Hélioparc, 2 avenue P. Angot, 64053 PAU Cedex 9, France

${ }^{2}$ Ecole des Mines d'Alès, 6 avenue de Clavières, 30319 ALES Cedex, France

\begin{abstract}
In 1963, Melamed proposed a model that expressed reflectance of a powder described as a population of spherical particles of unique diameter as a function of size, shape, and optical characteristics of the powder. This article shows how this model has been adapted to fit to industrial powders. An example of use for industrial quartz is given.
\end{abstract}

Key words: color formulation; reflectance; Kubelka-Munk; refractive index

\section{INTRODUCTION}

For economic reasons, it becomes more and more important for industrial pigments and fillers producers to control the colour reproducibility of their products. But, as colour of pulverulents depends on many parameters such as optical constants of the material (refraction index $\mathrm{n}$ and absorption coefficient k), size, shape, and arrangement of the particles, it is difficult to achieve.

In 1963, Melamed ${ }^{1}$ developed a model that directly expresses reflectance (from reflectance data, we have the information about the colour) as a function of these different parameters. This model is very different from the well-known Kubelka-Munk's model that is commonly used in industries for colour-matching problems. The Kubelka-Munk model is a "continuous" model, i.e., it considers that the medium, even if composed of dif-

*Correspondence to: Hélène Garay (e-mail: Helene.Garay@ema.fr) ferent components, is one material with its own optical properties. Its main advantage is to allow indirect reflectance sum because the coefficient of diffusion $S$ and the coefficient of absorption $K$ are additive and are related to the reflectance trough the Kubelka-Munk function.

Melamed's model is a "hybrid" model, since it can be considered "discrete" because the material is assessed to be composed of particles with their own physical and optical properties and it can be considered "continuous" because the sample is made of many particles in contact one with each other. In the case of discrete models, the reflectance is an individual property of the particle, and the aim is to make it become a collective property of the material by taking into account the arrangement of the particles, through the coefficient $x_{u}$ In this article, we give a tool adapted from Melamed's model. It is necessary to fit Melamed's initial model because it has been developed for an ideal case that is impossible to produce industrially. The adaptations are necessary to take into account granulometric distribution of the population (using the Kubelka-Munk function), other shape and arrangement of particles, and practical measurement geometry.

\section{PRESENTATION OF MELAMED'S MODEL ${ }^{1,2,3}$}

Melamed's model can be said to be macroscopic as it calculates reflectance of a global sample, taking into account all the rays that emerge upwards after one, two, or more interreflections in the bulk of the powder. But Melamed's sample is made of particles with their properties, whereas Kubelka and Munk, for example, in their well- 


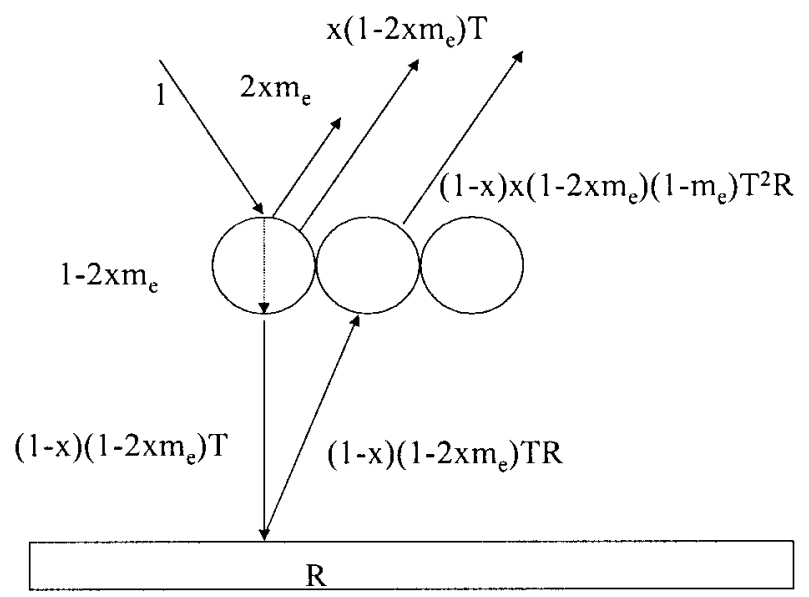

FIG. 1. Melamed's formalism (see following text for explanation of coefficients $x, m_{\mathrm{e}}$, and $T$ ). The first layer has been separated from the bulk for more clarity.

known theory consider the sample as a continuous medium with its own optical properties. This is very important for us, for we plan to be able to see and then to predict the influence of the modification of the properties of the particles on sample reflectance.

As Fig. 1 shows, Melamed established his formula by distinguishing the sample first layer (the surface) from the bulk of the powder, assumed to be a material of reflectance $R$. The model is based on geometrical optics laws (internal and external reflection, transmission, and absorption) so that a limitation appears about particle size, which must be much larger than the wavelength of the incident light.

Some authors have worked after Melamed on these types of models. ${ }^{2,3}$ This study has been carried out using Melamed's model, once the typographical errors corrected. The first attempt of Mandelis and all $^{2}$ to improve Melamed's model did not let us describe strongly absorbing materials and the second ${ }^{3}$ has not been studied yet.

Summing all the emerging rays, Melamed gets for reflectance $R$ the following:

$$
R=\frac{1+m_{\mathrm{e}}(A+B)+A C-\left\{\left[1+m_{\mathrm{e}}(A+B)+A C\right]^{2}\right.}{\left.-4\left(m_{\mathrm{e}}+C\right)(A+B)\right\}^{1 / 2}}
$$

where

$$
\begin{gathered}
A=2 x m_{\mathrm{e}} \\
B=x\left(1-2 x m_{\mathrm{e}}\right) T \\
C=(1-x)\left(1-m_{\mathrm{e}}\right) T .
\end{gathered}
$$

The parameters $T, x$, and $m$ are explained later. In his theory, Melamed uses several parameters that have a physical meaning.

\section{Absorption Constant $K$}

The absorption constant is classically given as follows:

$$
K=\frac{4 \pi k}{\lambda},
$$

where $k$ is the absorption coefficient of the material and $\lambda$ is the wavelength. In the model, the absorption constant is always associated with the diameter of the particles to form the dimensionless number $K d$.

\section{External and Internal Reflection Coefficients $m_{\mathrm{e}}$ and $\boldsymbol{m}_{\text {. }}$}

Both external and internal reflection coefficients have integral definitions derived from Lambert's law and Fresnel's coefficient as follows:

$$
m_{\mathrm{e}}(n)=2 \pi \int_{0}^{\pi / 2} R_{\text {spec }}(\alpha, n) I_{\alpha} \sin \alpha d \alpha
$$

$m_{\mathrm{i}}(n)=1-\sin ^{2} \alpha_{c}+2 \pi \int_{0}^{\alpha_{c}} R_{\mathrm{spec}}(\alpha, n) I_{\alpha} \sin \alpha d \alpha$

where $\alpha_{\mathrm{c}}$ is the critical angle for total reflection and $R_{\mathrm{spec}}$ is Fresnel's coefficient so that we have the following:

$I_{\alpha} R_{\mathrm{spec}}=\frac{1}{\pi} \cos \alpha \times \frac{1}{2}\left[\frac{\sin ^{2}(\alpha-\beta)}{\sin ^{2}(\alpha+\beta)}+\frac{\tan ^{2}(\alpha-\beta)}{\tan ^{2}(\alpha+\beta)}\right]$

\section{Coefficient $M$}

The $M$ coefficient contributes to transmission $T$ and corresponds to the part of a unitary internal radiation which reaches the other side of the particle after one crossing. It can be expressed as follows:

$$
M=\frac{2}{(K d)^{2}}\{1-(K d+1) \exp (-K d)\} .
$$

\section{Transmission $T$}

$T$ is the part of an incident radiation transmitted by one particle in any direction (i.e., not only in the forward direction). It can be expressed as a function of $M$ and $m_{\mathrm{i}}$ as follows:

$$
T=\frac{\left(1-m_{\mathrm{i}}\right) M}{1-m_{\mathrm{i}} M}
$$

$x$ and $x_{\mathbf{u}}$

$x$ is the probability that a ray emerges upward, taking into account the nature of the material (its absorption) and the neighboring particles. It depends on another coefficient, $x_{\mathrm{u}}$, which is characteristic of the geometry of the assembly. For spheres arranged in an hexagonal form, the value of $x_{\mathrm{u}}$ will be shown further to be 0.299 and 


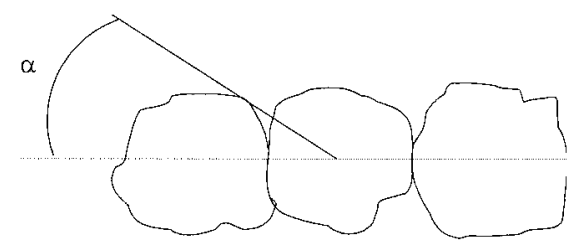

FIG. 2. Angle $\alpha$ and its dependence on particle shape.

$$
x=\frac{x_{\mathrm{u}}}{1-\left\{1-x_{\mathrm{u}}[1+\exp (-K d)]\right\} T} .
$$

Melamed developed his model for spheres, all of them of equal diameter and arranged in a compact hexagonal form. Since industrial powders never show such ideal properties, we have to fit the model to make it suitable for industrial powders. The fitting concerns the following parameters: $d$, $x_{\mathrm{u}}$, and $m_{\mathrm{e}}$.

\section{FITTING OF THE MODEL}

\section{Particle Size $d$}

Size of spherical particles can be described using their diameter as a unique parameter. For particles of any other shape, an optical equivalent diameter can be found which is the diameter that a spherical particle should have to show the same optical properties as the real particle. For this study, we decided to measure particle size by the technique of laser diffraction so that the equivalent diameter is the diameter of the sphere which scatters light in the same way as the particles. The instrument used was a Coulter LS 100.

To take into account the size distribution, the well-known Kubelka-Munk ${ }^{4}$ theory was used, which gives the diffuse reflectance as a function of two parameters, $K_{\mathrm{KM}}$ and $S_{\mathrm{KM}}$, which have an interesting property: they're additive for a mixture of different powders.

A product with a size distribution can be considered as a mixture, dividing the size distribution function into $m$ classes constituted of particles of diameter $d_{\mathrm{i}}$. Thanks to Melamed's model, reflectance $R_{\mathrm{i}}$ of the particles of this class can be calculated. Then, we can get the $\left(K_{\mathrm{KM}} / S_{\mathrm{KM}}\right)_{\mathrm{i}}$ value of each class using Kubelka-Munk's function as follows:

$$
\left(\frac{K_{\mathrm{KM}}}{S_{\mathrm{KM}}}\right)_{i}=\frac{\left(1-R_{i}\right)^{2}}{2 R_{i}} .
$$

There's a difference between reflectance according to Melamed and to Kubelka-Munk: it is the specular part, which is not taken into account by Kubelka and Munk and has to be taken away when calculating $K_{\mathrm{KM}} / S_{\mathrm{KM}}$. The specular part in Melamed's model can be expressed as $2 x m_{e}$ : on Fig. 1, it corresponds to the part of the incident radiation that is reflected at the surface of the sample without interacting with the bulk of the powder. Then knowing the following:

$$
\begin{aligned}
K_{\mathrm{KM}} & =\sum_{i=1}^{m} c_{i} K_{\mathrm{KM} i} \\
S_{\mathrm{KM}} & =\sum_{i=1}^{m} c_{i} S_{\mathrm{KM} i}
\end{aligned}
$$

$$
S_{\mathrm{KM} i}=\frac{a}{d_{i}} \quad a \in \mathfrak{R}
$$

we can sum the $\left(K_{\mathrm{KM}} / S_{\mathrm{KM}}\right)_{\mathrm{i}}$ to get the global $\left(K_{\mathrm{KM}} / S_{\mathrm{KM}}\right)$ of the product and using ${ }^{9}$ in reverse form, we calculate the sample total reflectance, to which the previously removed specular part is added.

Doing so we get the sample total reflectance, with the contribution of the particles of different size.

\section{Particle Shape}

Particle shape is taken into account by Melamed's model through a coefficient called $x_{\mathrm{u}}$. It represents the probability that a ray coming from the center of one particle emerges upwards without meeting another particle on its way. $x_{\mathrm{u}}$ is therefore linked to the notion of solid angle occupied by neighboring particles. Figure 2 shows that this solid angle will depend on particle shape (through $\alpha$ ).

Melamed calculated $x_{\mathrm{u}}$ for a compact hexagonal assembly of spheres (Fig. 3a). As ground industrial powders never show such perfect properties, we have chosen to consider revolution ellipsoids, arranged randomly (Fig. 3b). Two assumptions are made: ellipsoids are disposed according to their major axis and those of the upper layer are contained in the same plane.

For spheres, the calculation is rather simple, thanks to numerous symmetries. ${ }^{5}$ The solid angle $\omega$ occupied by each neighbor of the central particle is the same for the six particles and is equal to $2 \pi(1-\cos \alpha)$. This gives for $x_{\mathrm{u}}$ the following relation:

$$
x_{\mathrm{u}}=\frac{\left(2 \pi-6^{*} \frac{\omega}{2}\right)}{4 \pi} .
$$

In Eq. (11), $4 \pi$ is the total space, $2 \pi$ stands for the half top space, and $\omega$ is the solid angle occupied by one neighbouring sphere. So, we get a theoretical value for $x_{\mathrm{u}}$, which is 0.299 . This value is slightly different from Melamed's, which is 0.284 .

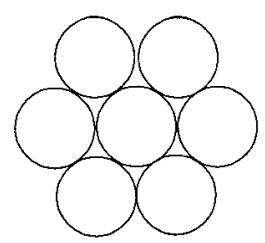

(a)

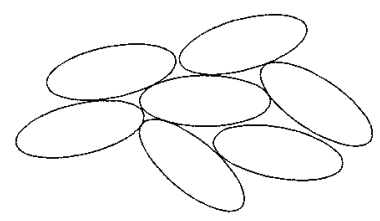

(b)
FIG. 3. Assembly of (a) spheres and (b) ellipsoids. 


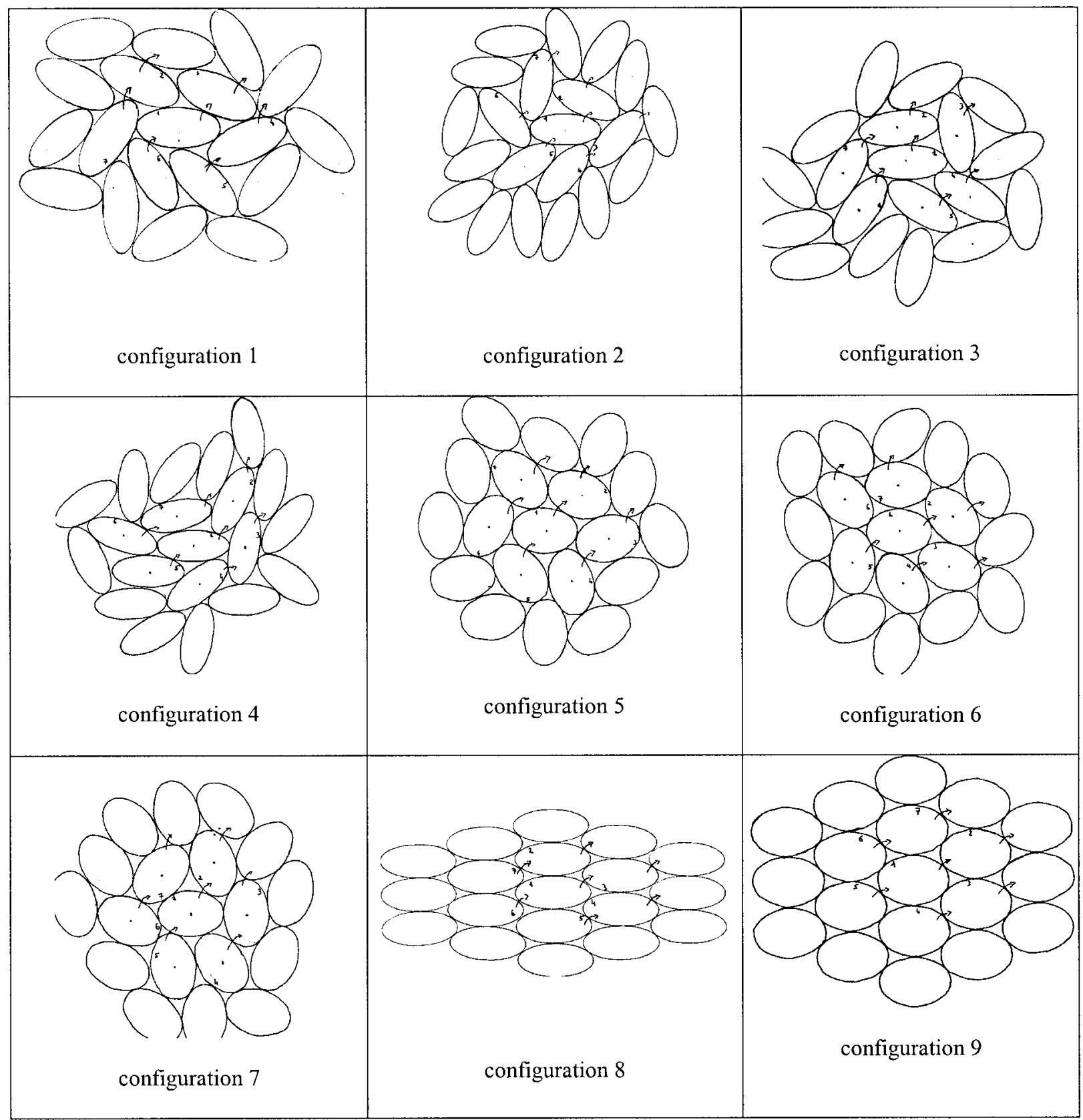

FIG. 4. A few possible configurations for revolution ellipsoids (top). Labels and arrows are useful only for the calculation code.

TABLE I. Variations of $x_{\mathrm{u}}$ for different randomly chosen configurations and for two different shapes of ellipsoids (long axis a/short axis $b$ ).

\begin{tabular}{cccccccccc}
\hline $\mathrm{a} / \mathrm{b}$ & Conf. $\mathrm{n}^{\circ}$ & Part. 1 & Part. 2 & Part. 3 & Part. 4 & Part. 5 & Part. 6 & Part. 7 & Mean value \\
\hline & 1 & 0.359 & 0.36 & 0.349 & 0.35 & 0.358 & 0.346 & 0.348 & 0.353 \\
& 2 & 0.348 & 0.355 & 0.344 & 0.355 & 0.357 & 0.356 & 0.367 & 0.355 \\
2.33 & 3 & 0.344 & 0.33 & 0.358 & 0.369 & 0.356 & 0.335 & 0.339 & 0.347 \\
& 4 & 0.337 & 0.338 & 0.354 & 0.349 & 0.343 & 0.352 & 0.334 & 0.344 \\
& 8 & 0.334 & 0.334 & 0.334 & 0.334 & 0.334 & 0.334 & 0.334 & 0.344 \\
& 5 & 0.327 & 0.324 & 0.321 & 0.328 & 0.334 & 0.322 & 0.327 & 0.326 \\
1.44 & 6 & 0.323 & 0.327 & 0.329 & 0.331 & 0.329 & 0.327 & 0.323 & 0.327 \\
& 7 & 0.325 & 0.329 & 0.326 & 0.329 & 0.325 & 0.334 & 0.321 & 0.327 \\
& 9 & 0.324 & 0.324 & 0.324 & 0.324 & 0.324 & 0.324 & 0.324 & 0.324 \\
\hline
\end{tabular}




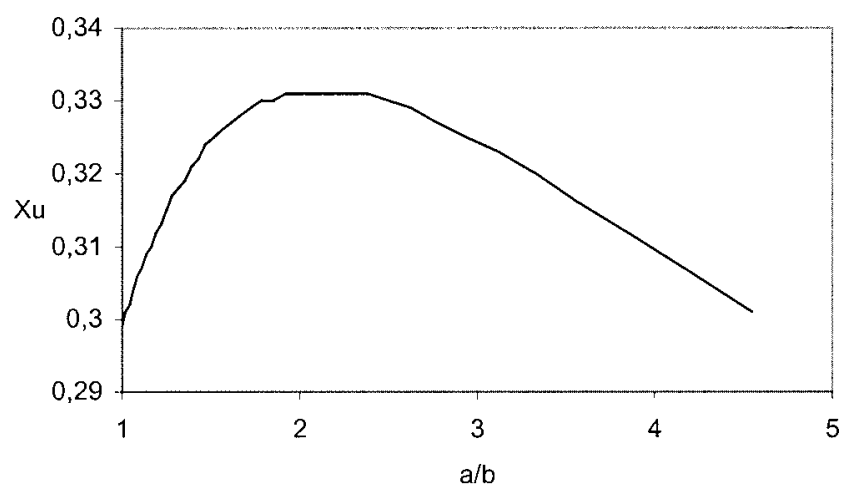

FIG. 5. $\quad x_{\mathrm{u}}$ as a function of the $a / b$ (long axis/short axis) ratio of the ellipsoids.

For revolution ellipsoids, the problem is more complicated because, following the relative position of the particles, the ray coming from one particle center will not "see" all the neighboring particles in the same way (i.e., the solid angle is not the same for all the surrounding particles). The details of the calculation are given elsewhere. ${ }^{6}$

The general idea is to consider that, when a measurement is done, a lot of particles are taken into account. Knowing this, how does $x_{\mathrm{u}}$ vary when more ellipsoids are accounted for when estimating $x_{\mathrm{u}}$ ?

Different random configurations of revolution ellipsoids, corresponding to two different shape of particles (long axis/short axis) are presented in Fig. 4. Table I gives all the calculated values of $x_{\mathrm{u}}$ for each particle, and the mean value obtained when making each particle is the center. We can note that when the ellipsoid shape tends to the sphere, the variations of the calculated values for $x_{\mathrm{u}}$ are less important.

We can note too that, when more particles are taken into account (seven instead of one), $x_{\mathrm{u}}$ is less variable, particularly for ellipsoids with an $a / b$ ratio close to 1 . So we conclude that $x_{\mathrm{u}}$ can be considered independent on the chosen configuration. Then, Fig. 5 shows the variation of $x_{\mathrm{u}}$ versus the $a / b$ ratio of the ellipsoids. $x_{\mathrm{u}}$ first increases with $a / b$ until a maximum corresponding to $a / b=2$. Then $x_{\mathrm{u}}$ decreases: the value for spheres $(0.299)$ is found again for $a / b=4.5$.

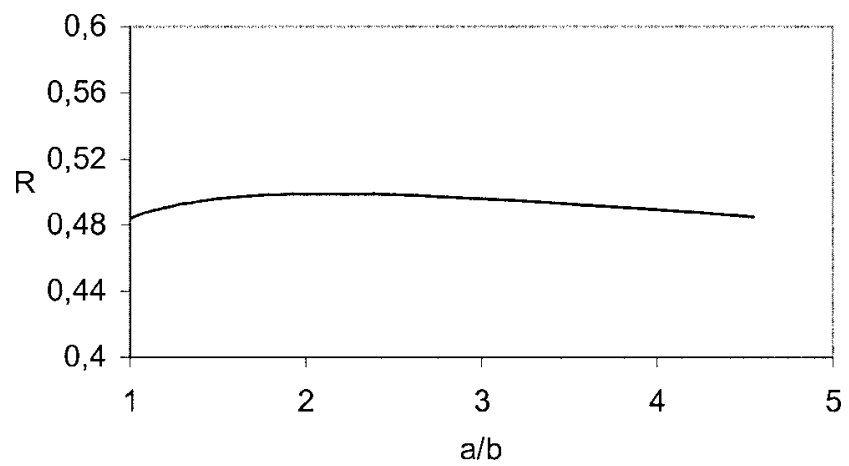

FIG. 6. Variation of reflectance as a function of the $a / b$ ratio, with $n=1.55, k=1.10^{-4}, d=30 \beta \mathrm{m}$, and $\lambda=456 \mathrm{~nm}$ (valid for usual values of $n, k, d$, and $\lambda$ ).

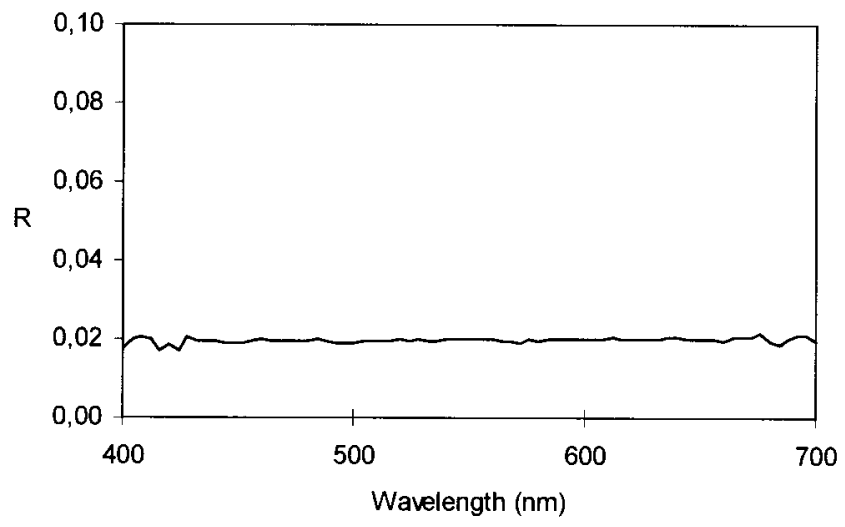

FIG. 7. Experimental reflectance spectrum of a sample of black coal.

To evaluate the influence of $x_{\mathrm{u}}$ variations, reflectance according to Melamed's equation can be calculated using with the different values of $x_{\mathrm{u}}$, all other variables of the model kept constant.

It can be observed on results displayed by Fig. 6 that the variations of reflectance are weak and justify the approximation : the value of $x_{\mathrm{u}}$ can be taken equal to 0.299 , for all shapes of particles. Calculations have been made with usual values for $n(1.3<n<3.5), k\left(10^{-8}<k<10\right)$, and $d(5$ $\mu \mathrm{m}<d<300 \mu \mathrm{m})$.

\section{Coefficient $\boldsymbol{m}_{\mathrm{e}}$}

The $m_{\mathrm{e}}$ coefficient has to be fit because our measurement apparatus cannot fulfill Melamed's geometrical assessments. Melamed considered that all the rays that emerge out of the sample will be collected by the detector: without an adequate device (e.g., an integrating sphere), this is impossible. Because our purpose is to propose an industrial solution for controlling the reflectance of powders, we do not want to impose lab conditions for the measurements. The sample is placed in a room lighted only with two fluorescent tubes, always in the same geometry. In this study we used a PhotoResearch PR 650 spectroradiometer, which allows reflectance spectrum measurement in any desired geometrical configuration, under a chosen light source. The geom-

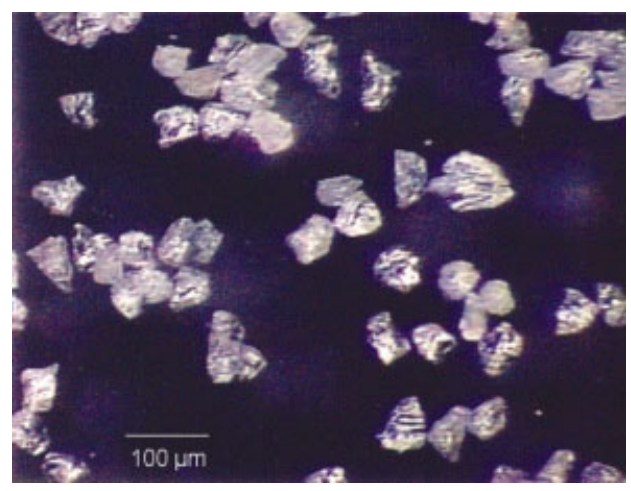

FIG. 8. Size fraction $75-80 \mu \mathrm{m}$ of quartz viewed through an optical microscope 


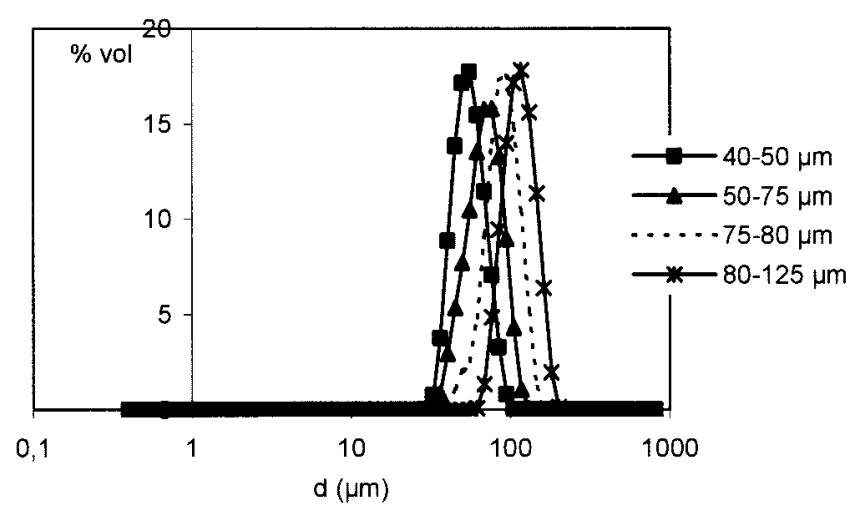

FIG. 9. Size distribution of the four classes of quartz.

etry we chose allowed the detector to collect the rays that emerged near the normal to the sample. In Melamed's model, the coefficient that takes this into account is $m_{\mathrm{e}}$. Its integral definition [Eq. (4.1)] accounts for all the rays (i.e., in any direction). Since it is very difficult to estimate mathematically the value of $m_{\mathrm{e}}$ corresponding to the measurement geometry, we used an empirical method based on the observation that when a product has a very strong absorption coefficient $k$, the reflectance according to Melamed tends toward $2 x_{\mathrm{u}} m_{\mathrm{e}}$. We prepared and measured a sample of finely ground black coal, which is a very strongly absorptive product. As expected, the reflectance spectrum curve is rather planar and has a weak value (Fig. 7). So, knowing $x_{\mathrm{u}}$, we can deduce a value for $m_{\mathrm{e}}$. The mean measured reflectance for black coal is 0.0196 . So we get the following:

$$
m_{\mathrm{e}}\left(n_{\text {coal }}\right)=\frac{\bar{R}}{2 x_{\mathrm{u}}}=0.033
$$

But $m_{\mathrm{e}}$ depends on the refraction index $n$ of the material. We then calculate the ratio between the theoretical coefficient $m_{\mathrm{e}}$ and the real one as follows:

$$
\tau=\frac{m_{\mathrm{e} \text { Fresnel }}}{m_{\mathrm{e} \text { estimated }}}
$$

The refraction index of coal is 2.197, which leads [Eq. (4.1)] to a theoretical value for $m_{\mathrm{e}}$ of 0.186 and gives a value of $\tau$ ratio equal to 5.63. Because the difference is mainly linked to geometrical considerations, we make the assumption that

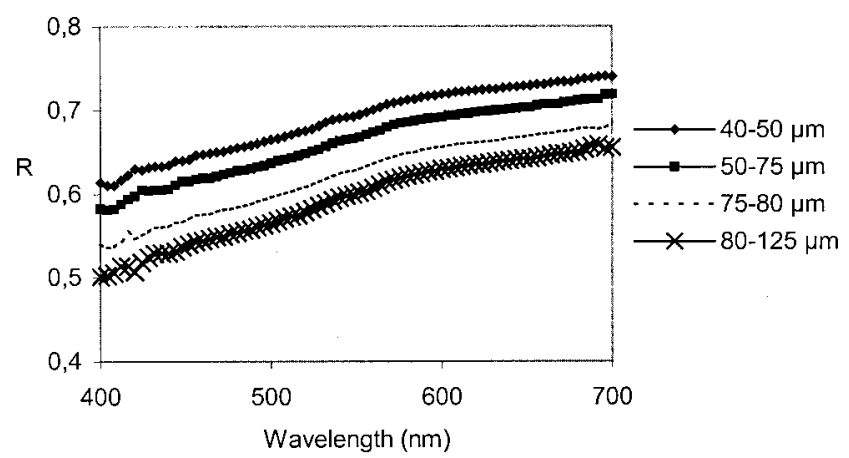

FIG. 10. Measured reflectance of the four classes of quartz.

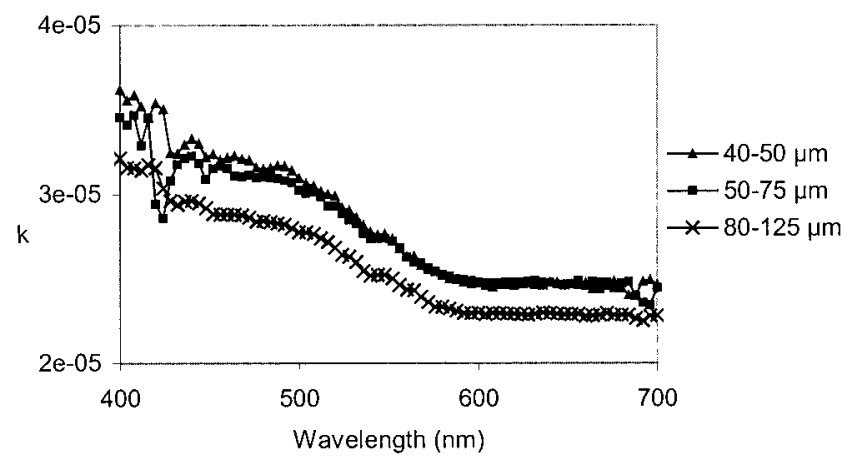

FIG. 11. Calculated absorption spectrum of the 40- to $50-\mu \mathrm{m}, 50-$ to $75-\mu \mathrm{m}$, and $80-$ to $125-\mu \mathrm{m}$ classes.

this ratio does not depend on the refraction index $n$ of the material. Then, the condition to apply this ratio is that all the measurements should be made in precisely the same conditions, particularly concerning the source/sample/detector geometry.

\section{USE OF THE MODEL}

To use the model, a calculation code has been developed. A user interface is proposed to choose the calculation: prediction of reflectance or calculation of absorption coefficient.

Four different size classes of a an industrial quartz were first obtained by careful sieving of a commercial product. These classes are named 40-50 $\mu \mathrm{m}, 50-75 \mu \mathrm{m}, 75-80 \mu \mathrm{m}$, and 80-125 $\mu \mathrm{m}$ according to the sieves used to separate them. Figure 8 shows the 80 - to $125-\mu \mathrm{m}$ size fraction of this quartz. The size distributions of the four fractions measured by laser diffraction technique are shown on Fig. 9 .

Figure 10 shows the four classes measured reflectance. Reflectance increases as expected with decreasing particle size. Using three of the four classes, three absorption spectra were determined numerically, using the hypothesis that Melamed's equation can be used in a reverse way if $n^{*}, d$, $x_{\mathrm{u}}$, and $\lambda$ are known. The results of these calculations are given on Fig. 11.

* For many minerals, $\mathrm{n}$ can be easily known ${ }^{7}$

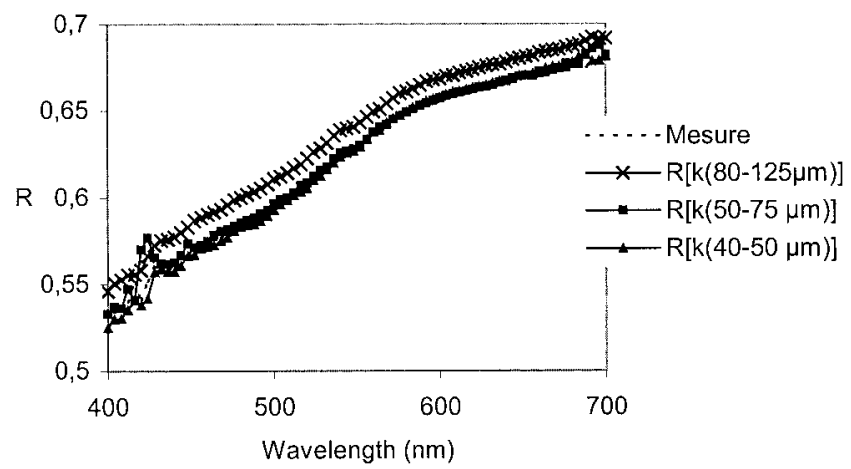

FIG. 12. Reflectance measure of the $75-$ to $80-\mu \mathrm{m}$ class compared to the simulations. 
TABLE II. $\Delta E$ between measured and simulated spectra using $k$ values calculated from three samples.

\begin{tabular}{ccc}
$\begin{array}{c}80-\text { to } 125-\mu \mathrm{m} \\
\text { sample }\end{array}$ & $\begin{array}{c}50-\text { to } 75-\mu \mathrm{m} \\
\text { sample }\end{array}$ & $\begin{array}{c}40-\text { to } 50-\mu \mathrm{m} \\
\text { sample }\end{array}$ \\
\hline 0.768 & 0.374 & 0.326 \\
\hline
\end{tabular}

Using these calculated absorption spectra, we can simulate the reflectance that the three classes would have if they had the size distribution of the fourth class, $75-80 \mu \mathrm{m}$. Figure 12 compares these three simulations compared to the measured reflectance of the $75-$ to $80-\mu \mathrm{m}$ class.

We have calculated the CIE color difference between each simulation and the measure. They are given in Table II.

\section{CONCLUSION}

This work shows that Melamed's model can be fitted to be applied to industrial powders taking into account their size distribution and nonspherical shape. The result that shows that $x_{\mathrm{u}}$ can be kept constant for revolution ellipsoids proves that the individual property of shape of the particles is less important than the collective properties of the population.

This model, thanks to the explicit expression of reflec- tance as a function of physical parameters, provides better control of the reflectance of the powder. It is possible to envisage including it in a control system for the production of industrial powders because it becomes possible to predict the reflectance of a material knowing its size distribution and the reflectance of another size distribution of the same material.

1. Melamed NT. Optical properties of powders. Part I: Optical absorption coefficients and the absolute value of the diffuse reflectance. J Appl Phys 1963;34:560-570.

2. Mandelis A, Boroumand F, Van Den Bergh H. Quantitative diffuse reflectance spectroscopy of large powders: the Melamed's model revisited. Appl Optics 1990;29:2853-2860

3. Mandelis A, Boroumand F, Van Den Bergh H. Quantitatively diffuse reflectance and transmittance of loosely packed powders. Spectrochim Acta 1991;47:943-971.

4. Kortüm G. Reflectance spectroscopy. Berlin: Springer-Verlag; 1969

5. Callet P De l'effet de la mouture des pigments sur la couleur des poudres et des pigments. Rev Int CFAO Infograph 1994;9:831-845.

6. Bozec-Garay H. Paramètres morphogranulométriques et comportement optique des matériaux divisés. Mise en œuvre d'un modèle de diffusion en vue de son application à des opérations industrielles sur des poudres minérales. Ph.D. thesis, Ecole des Mines de Saint-Etienne and INP of Grenoble, 2000.

7. Palik ED. Handbook of optical constants of solids. New York: Academic Press; 1985. 